\title{
Reconstruction and optimization methods of old university teaching buildings
}

\author{
Shao Siyu ${ }^{1, *}$ \\ ${ }^{1}$ Changchun Institute Of Technology, 130012, Jilin, China
}

\begin{abstract}
This paper mainly studies the reconstruction of the old teaching building in China. There are many buildings in our country, aging phenomenon is serious, indoor teaching mode is not suitable for modern education. Through the analysis of the main existing problems of indoor environment, the paper puts forward the suitable renovation scheme from the aspects of energy allocation, indoor thermal environment and comfort, so as to make the teaching building suitable for the use of modern education.
\end{abstract}

\section{The necessity of teaching building renovation}

In China, many colleges and universities have a long history of running schools, parts of the campus buildings and landscape have a history of more than half a century. Although they contain profound historical and cultural values, these buildings now face the problem that they cannot meet the requirements of modern teaching. In addition, the aging problem of the building itself is also very prominent. In terms of the safety, function and comfort of the building, the renovation of this kind of building is imperative.

\section{Direction of modern teaching building renovation}

Teaching building building is the main place of knowledge dissemination, its planning and design must be influenced by the concept of education, and with the development of society constantly revised and changed. In order to make the teaching building adapt to the needs of modern teaching methods, its design has been divided into functional diversification. As an architect, we have the responsibility and obligation to create an efficient, safe, comfortable and beautiful interior space for students by optimizing the design method and applying the concept of sustainable design. In this paper, by analyzing the specific contents and design methods of the teaching building interior space in the actual design, and by combining the theory and practice, the author explores the methods of the adaptive transformation of the teaching building in colleges and universities.

\subsection{Rebuilding in the direction of information and networking}

With the development of information technology and computer network, modern education has undergone a great reform. The brand-new teaching method has put forward the brand-new demand to the teaching place design, the traditional classroom has been unable to satisfy the modern teaching method request, the campus building intelligence is the construction modern university must must do. In addition to the traditional space for teachers and students to interact with each other, modern teaching needs to consider the installation of facilities for modern teaching, so as to ensure the facilities and reasonable installation as well as the convenient and efficient use in the teaching process.

\subsection{Functional comprehensive reconstruction}

Due to the limited land area in the campus, it is more important to improve the utilization rate of buildings and increase the teaching of single buildings with more functions. The relationship between the condition of a building and student attitudes and behavior was reported in one study cited here. As can be expected, students in the newly modernized building had better attitudes and fewer disciplinary behaviors than students in school buildings that were old and dilapidated. ${ }^{[1]}$ In recent decades, a major trend has been for buildings to adopt a mixed-use approach, which can increase the use rate of a single building. Therefore, it is undoubtedly the right choice for the teaching building to develop towards the trend of functional integration, which is not only in line with the reform trend of college education, but also conducive to the cooperation and communication between teachers and students of different majors, so as to promote the common development of all disciplines and expand the development direction of disciplines. It is

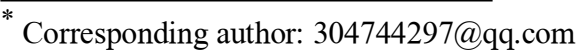


known that classroom spatial arrangements with welldefined areas can have a positive influence on students' social interaction and cooperation. ${ }^{[2]}$ In addition, the comprehensive construction of university buildings can also alleviate the problem of land shortage on campus.

\section{Implementation plan of building reconstruction}

Based on the above analysis of the existing problems in the renovation of teaching buildings and the trend of teaching reform, the following renovation and optimization schemes are proposed. Building an intelligent and humanized teaching environment should be the main goal of the teaching building renovation. Whether the design of its space layout, ventilation, lighting and pedestrian lines is efficient, safe and energysaving is the main content of the transformation.

\subsection{Optimization of teaching building infrastructure}

With the popularization of modern teaching, there has been a great demand for the application of computers and telecommunication equipment in the teaching buildings. Even after the completion of many teaching buildings, the wiring system and new equipment are often modified and added. The computer network in the teaching building, in the consideration of how many equipment room is reasonable, not only to consider the current use needs, but also to consider the future transformation needs. Therefore, in order to meet the needs of mechanical and electrical equipment changes in the future, more equipment rooms and pipe Wells should be separated in architectural design to reserve enough space for future partial transformation.

The selection of materials should be based on the region where the building is located and the local climatic characteristics. China is a vast region with great climate difference between the north and the south. In the process of selecting building materials, the principles of thermal design of buildings issued by the state should be followed first. For example, table 1 is the principles of thermal design of China, which is of great reference value to the design work. The focus of the architect's work is to choose the best scheme for construction according to the actual situation.
Table 1. Thermal design area ${ }^{[3]}$

Building thermal design level 1 zoning index

\begin{tabular}{|c|c|c|}
\hline \multirow{2}{*}{$\begin{array}{l}\text { Primary } \\
\text { division name }\end{array}$} & \multicolumn{2}{|c|}{ Regionalization indicators } \\
\hline & Main indicators & $\begin{array}{l}\text { Auxiliary } \\
\text { indicators }\end{array}$ \\
\hline $\begin{array}{l}\text { Severe Cold } \\
\text { region }\end{array}$ & $t_{\min } \cdot \mathrm{m} \leqslant-10^{\circ} \mathrm{C}$ & $145 \leqslant d \leqslant 5$ \\
\hline Cold region & $-10^{\circ} \mathrm{C}<t_{\min } \cdot \mathrm{m} \leqslant 0^{\circ} \mathrm{C}$ & $90 \leqslant d \leqslant 5<145$ \\
\hline $\begin{array}{l}\text { Hot summer and } \\
\text { cold winter } \\
\text { region }\end{array}$ & $\begin{array}{c}0^{\circ} \mathrm{C}<t_{\min \cdot \mathrm{m}} \leqslant 10^{\circ} \mathrm{C} \\
25^{\circ} \mathrm{C}<t_{\max } \cdot \mathrm{m} \leqslant 30^{\circ} \mathrm{C}\end{array}$ & $\begin{array}{c}0 \leqslant d \leqslant 5<90 \\
40 \leqslant d \geqslant 25<110\end{array}$ \\
\hline $\begin{array}{l}\text { Hot summer and } \\
\text { warm winter } \\
\text { region }\end{array}$ & $\begin{array}{c}10^{\circ} \mathrm{C}<t_{\min \cdot \mathrm{m}} \\
25^{\circ} \mathrm{C}<t_{\max } \cdot \mathrm{m} \leqslant 29^{\circ} \mathrm{C}\end{array}$ & $100 \leqslant d \geqslant 25<200$ \\
\hline Moderate region & $\begin{array}{c}0^{\circ} \mathrm{C}<t_{\text {min }} \cdot \mathrm{m} \leqslant 13^{\circ} \mathrm{C} \\
18^{\circ} \mathrm{C}<t_{\text {max }} \cdot \mathrm{m} \leqslant 25^{\circ} \mathrm{C}\end{array}$ & $0 \leqslant d_{\leqslant 5}<90$ \\
\hline
\end{tabular}

The effect of thermal energy storage in the building envelop is to reduce the indoor temperature fluctuations and to delay the air temperature extremum. Thermal energy is usually stored in the building envelop by sensible heat of the materials. ${ }^{[4]}$ The architect should choose materials that are more suitable for heat dissipation according to the climatic characteristics of the region, choose materials with better heat storage if it is cold all year round, and consider the heat dissipation of materials if it is hot in summer.

\subsection{Rational planning of regional functions}

As a modern teaching building, functional requirements must be met in the first place. The method of rational functional planning is to separate the administrative office from the classroom and laboratory in the plane layout to make the plane layout as flexible as possible. For example, in order to achieve a more efficient evacuation, the main passageways can be arranged separately, and different use units of different properties can be formed on the same surface. Different functional Spaces occupy their own evacuation requirements, and they also have strong interactivity. In order to adapt to the overall trend of the development of modern education, the teaching building, in the recovery of consolidation should pay attention to the related disciplines, to provide different disciplines of workers have been using concentrated teaching facilities as far as possible, so that not only is advantageous to the cooperation between the subjects, but also to the use and management of equipment, reduce the cost of buying equipment and energy consumption. 


\subsection{Improve the comfort of the environment}

Comfortable learning environment is conducive to teachers' teaching with a more stable attitude, and can also improve students' learning efficiency. Comfortable indoor temperature is also an important condition to maintain human health. In general, there has been growing recognition that occupant interaction with the building and its systems is a significant determinant for occupant satisfaction and thermal responses and that the biggest threat to occupant satisfaction occurs when a building and its systems are too complicated, unintelligible, or unresponsive to occupant control behaviors. ${ }^{[4]}$ In general, there has been growing recognition that occupant interaction with the building and its systems is a significant determinant for occupant satisfaction and thermal responses and that the biggest threat to occupant satisfaction occurs when a building and its systems are too complicated, unintelligible, or unresponsive to occupant control behaviors. [5]

\subsubsection{Indoor thermal balance}

Thermal balance is one of the main conditions for people's health and comfort. The thermal sensation of human body is mainly related to the thermal balance of the whole body. The stimulation of indoor temperature to human body is a dynamic process, as shown in table 2 .

Table 2. Hot and cold stimulation under dynamic conditions
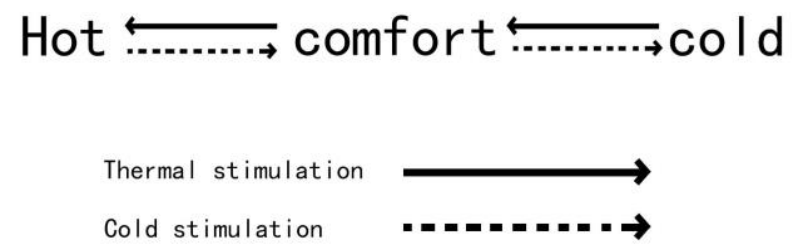

When the human body feels hot, cold stimulation will restore the human body to a comfortable state, but too much cold stimulation will make people feel uncomfortable again, and the opposite situation is the same. Therefore, the envelope structure in the selection of materials from two aspects, when the summer heat, should keep the indoor heat to reach the appropriate temperature and no longer rise, when the winter cold can effectively prevent the indoor temperature to fall too quickly. Proper enclosure structure will make the indoor temperature stable and good, at the same time must take into account the influence of the heating system, the sun and the ventilation system. The existence of large, usually non-occupied, public spaces in school buildings enables their utilization as buffer zones for pre-warming the fresh ventilation air in winter, and for increasing removal of heat stored in classrooms' floors and walls in summer. ${ }^{[6]}$

\subsubsection{Humanized reconstruction}

When we rebuild the building, we need to be aware that it is not only a space for teaching, but also a space for teachers and students to socialize and rest together. Although the teaching building is a space for collective use, it should also take into account the functional requirements of students' individual activities. As much as possible, a wide variety of functions should coexist in a common area without conflict. Under the precondition of reasonable, to be in the office space as much as possible the arrangement which has the function of various equipment, a variety of functions are derived from the converted into a space, each function is not fixed interval, they can be either the area of self-study, also can be a social area, that cater to the self-study in the form of the illicit close sex of the need, also meet the openness of the social needs. We should also fully explore the history and culture of the school and create a building with unique humanistic spirit.

\section{Conclusion}

The reconstruction of old teaching buildings is an important part of modern higher education, which is also in line with the development trend of reducing resource waste and green and sustainable development. The reform of teaching buildings in colleges and universities is bound to be accompanied by the reform of educational methods. There are too many factors to consider in this process, such as the changes in modern people's living habits, the continuous emergence of new construction technologies, as well as the numerous problems of saving resources and reducing environmental pollution in society. University campus is an important part of the social construction, but also needs to bear a lot of social responsibility, It is of great practical significance to choose the optimal transformation scheme for protecting the environment, maintaining the ecological balance and the sustainable development of human society has great practical significance.

\section{Conclusion}

The reconstruction of old teaching buildings is an important part of modern higher education, which is also in line with the development trend of reducing resource waste and green and sustainable development. The reform of teaching buildings in colleges and universities is bound to be accompanied by the reform of educational methods. There are too many factors to consider in this process, such as the changes in modern people's living habits, the continuous emergence of new construction technologies, as well as the numerous problems of saving resources and reducing environmental pollution in society. University campus is an important part of the social construction, but also needs to bear a lot of social responsibility, It is of great practical significance to choose the optimal transformation scheme for protecting the environment, maintaining the ecological balance and the sustainable development of human society has great practical significance.

\section{References}

1. Earthman, Glen, I, Linda Lemasters.Review of Research on the Relationship between School Buildings, Student Achievement, and Student 
Behavior,Linda Lemasters Gloucester County Public Schools[D],(1996)

2. Nuria C, Carmen L, et al. Subjective assessment of university classroom environment[J]. Building and Environment, (2017)

3. Code for thermal design of civil building GB 501762016

4. 4. A review on phase change materials integrated in building walls F. Kuznik, D. David, et al. Renewable and Sustainable Energy Reviews,2011.

5. De Dear R J, Akimoto T, Arens E A, et al. Progress in thermal comfort research over the last twenty years[J]. Indoor Air, 2013, 23(6):442-461.

6. de Dear, R. J,Akimoto, T,et al. Progress in thermal comfort research over the last twenty years Indoor Air,(2013)

7. Becker R, Goldberger I, Paciuk M. Improving energy performance of school buildings while ensuring indoor air quality ventilation[J]. Building and Environment, (2007) 